\section{Recent Advances in Anatomy}

Edited by F. GoldBY, M.A., M.R.C.P., and R. J. Harrison, M.A., M.D., D.sc. Second series. Pp. ix + 477, with 9I illustrations. London: J. \& A. Churchill. 1961. 6os.

The first edition of ' Recent Advances in Anatomy' appeared in 1927; since that time the scope and interests of anatomy have altered considerably so that today it is difficult to define its margins. According to the late Professor Woollard, who edited the first edition, 'Anatomy is what anatomists do' and the present volume gives a remarkably concise cross-section of the wide range of interests of the modern anatomist. The chapters include sections on the exocrine secretory cells, the endoctines, reproductive tissues, the repair of epithelia, the nervous tissues, joints, the anatomy of the lung, the blood supply of the liver, spleen and kidney, and a final chapter on primate evolution.

The text reflects the new weapons which anatomists now possess-electron microscopy, tissue culture, radioactive isotopes-transporting their activities from those of purely descriptive morphology to detailed laboratory in vestigations.

Obviously the super-specialist will find the chapter in his own field too brief; this book is to be remembered as a most useful reference for the non-specialist, who will discover useful accounts of advances in adjacent fields to his own. If his appetite is sufficiently wetted, he will find an up-to-date bibliography well garnished with key references for his further reading.

\section{Tropical Radiology}

Howard Middlemiss, M.D., F.F.R., D.M.R.D. Pp. $x+272$, illustrated. London: William Heinemann. i96r. 6os.

Books on medicine and surgery in the tropics tend to fall into two main groups: those that deal with modifications of accepted medical practice already, at least partially, covered in existing textbooks and those which break entirely new ground.

This splendid new book on tropical radiology, edited by Dr. Middlemiss, falls into the latter group and fills a gap in medical literature for those who work in the tropics or are interested in this field of medicine.

With the rapidly developing medical services in the under-developed countries X-ray facilities are becoming more readily available even in the most isolated and ' bush ' hospitals, but the provision of trained radiologists to interpret the difficult X-ray has lagged far behind and most doctors working in these regions have therefore to learn to interpret their own films.

Dr. Middlemiss helps them to do just that. $\mathrm{He}$ provides the clues to the diagnosis of all the common and most of the uncommon tropical diseases. These details of radiological diagnosis are for the most part non-existent in the textbooks on radiology at present available.

The book deals with the radiological aspect of tropical disease so comprehensively and with such authority that one is tempted to say that Dr. Middlemiss and his collaborators have produced a definitive work on the subject. But knowledge of these diseases is increasing so rapidly that, as the editor suggests in his preface, many of the contributions will in later years come to be regarded only as introductions to the subject, and further editions will undoubtedly be required to keep the subject matter up to date and maintain the high standard already achieved.
The first section is concerned with bone and joirf disease. Besides covering the specifically tropical diseas and nutritional abnormalities, it deals with the tropicis manifestations of tuberculosis and gross chronic osteamyelitis now seen in their most florid forms only in the under-developed countries. One would like to see a $X$-ray of the common whole shaft sequestrum of long bones and also perhaps a better film of the maduramye cosis. Fig. V (4) in the section on brucellosis is not u. to the standard of the other films.

There is then an excellent section by Dr. Cockshot on the interesting subject of the hæmoglobin diseases and other sections follow on the parasitic disease cardiovascular and pulmonary diseases, and the diseaseg of the alimentary and genito-urinary tracts. A final section deals with neoplasms and the differences betwee $\overrightarrow{n_{1}}$ the types of malignancy seen in various parts of thy world. In this latter section the chapter on cancer West Africa does not mention the commonest form os cancer of all, that supervening on chronic leg ulcers. This is, however, mentioned elsewhere and also in thi् chapter on cancer in East Africa, where it gets two pages on its own.

This section also discusses the subject of lymphom a common type of multifocal lymphosarcoma usualiff presenting as a jaw tumour. This is at present thee subject of some intensely interesting research by Bures kitt, who has found that there is a definite pattern o $\Phi$ geographical distribution in Africa and that areas where the temperature never drops below $60^{\circ} \mathrm{F}$. ar those where this tumour is found. This is roughly 1 क on either side of the equator. It is thought that this ma£ indicate a virus origin for the disease.

The general layout and presentation is good and cohe reproduction of $\mathrm{X}$-rays throughout the book is general of a very high standard, though one $\mathrm{X}=\mathrm{fag}$ enjoys the distinction of being printed upside downe- ?

Altogether this is a most valuable book and shouldib read, digested and, if possible, owned by everyone work ing in the tropics. Even for those not directly concerned with the reading of $\mathrm{X}$-rays there is a wealth of clear an $\bar{\Phi}$ concise general information which is not easily foun elsewhere.

\section{'Curare and curare-like agents' Ciba Foundation Study Group No. 12}

Edited by A. V.S. DE REUCK, M.SC., D.I.C., A.R.C.SPp. viii +103 with 26 illustrations. London? J. \& A. Churchill. I962. 12s. $6 \mathrm{~d}$.

This slim volume of 98 pages with 28 figures, five tables and numerous structional formulæ drawn in full contains a wealth of information. There are variations is the size of print which does not make for ease of reading but at the modest price of $12 s .6 d$. it is good value.

On July 4, 1961 the Ciba Foundation study group number 12 met under the Chairmanship of Dr. Feldber to discuss certain aspects of 'curare and curare-like. agents', and this is a report of the papers delivered, together with their subsequent discussion. The distinguished contributors include such internationall famous authorities on the physiology and pharmacolog? of neuro-muscular block as Ariens, Bovet, Chagas 60 Paton and Zaimis.

Though the book may be a 'must' for potentiaT professors, it is doubtful if the average clinician will be much the wiser even after several readings. This however should not deter those with an inquisitive mind? and some time to spare, from acquainting themselveso with the intriguing complexity of modern research in the field. 